\title{
EDITORIAL
}

\section{Tough at the top: must end-expiratory lung volume make way for end-inspiratory lung volume?}

\author{
Yuan Ming Luo*, Nicholas S. Hopkinson" and Michael I. Polkey ${ }^{\#}$
}

A reduced exercise capacity, which limits the performance of activities of daily living and social participation, is a cardinal feature of chronic obstructive pulmonary disease (COPD). Breathlessness is the main limiting symptom, although, depending on the task undertaken [1], leg discomfort is prominent in a substantial minority of patients. Dyspnoea arises through the interplay of pulmonary manifestations of COPD (airflow obstruction, emphysema and destruction of the pulmonary vascular bed) [2], systemic effects of the disease [3] and neural mechanisms [4,5]. These complex relationships remain incompletely understood. Traditionally, both the severity of COPD and the efficacy of treatment interventions have been assessed using resting lung function measures, particularly forced expiratory volume in $1 \mathrm{~s}$ (FEV1). However, health status is more closely associated with lung volume measurements [6] than FEV1, and bronchodilator-based therapies can improve lung volumes at rest [7] and during exercise [8] without change in FEV1, prompting interest in the study of dynamic lung volumes and dyspnoea arising during exercise.

The metabolic demands of exercise at a given intensity require a corresponding minute ventilation in order to sustain them. Indeed, the levels of ventilation achievable during exercise in relation to oxygen consumption or carbon dioxide production are used as measures of cardiopulmonary fitness (e.g. before surgery). An increase in ventilation can occur through an increase in tidal volume or respiratory rate. Healthy individuals can increase their tidal volume during exercise by breathing out further to a lower end-expiratory lung volume (EELV) by contracting their abdominal muscles [9]. This manoeuvre serves both to lengthen the diaphragm, increasing the contractile power of the inspiratory muscles [10], and also to cause cranial movement of the abdominal contents. Since exercise is usually conducted in an upright position, subsequent inspiration is facilitated by their descent.

In COPD, the likelihood of EELV increasing with increased minute ventilation is suggested by data presented in 1934 by Ronald Christie who presciently noted "The chest is already in the inspiratory position, with a consequent diminution of complemental air and inability to produce any significant

\footnotetext{
*State Key Laboratory of Respiratory Disease, Guangzhou Medical College, Guangzhou, China. ${ }^{*}$ NIHR Respiratory Biomedical Research Unit, Royal Brompton and Harefield NHS Foundation Trust and National Heart \& Lung Institute, Imperial College London, London, UK.

CORRESPONDENCE: M.I. Polkey, NIHR Respiratory Biomedical Research Unit, Royal Brompton Hospital, Fulham Road, London, SW3 6NP, UK. E-mail: m.polkey@rbht.nhs.uk
}

increase in inspiratory depth. Expiratory depth also cannot be increased owing to diminution, or even obliteration, of the reserve air" [11]. By 1971, POTTER et al. [12] were able to measure flow-volume loops during treadmill exercise. They showed that both EELV and end-inspiratory lung volume (EILV) were shifted substantially upwards in a small group of patients with COPD.

Recently, several studies have suggested that dynamic hyperinflation is the most important mechanism causing exercise limitation due to dyspnoea in patients with COPD. For example, O'DONNELL et al. [13] showed that decline in inspiratory capacity during exercise, an index of hyperinflation, is closely related to the magnitude of dyspnoea, and several data suggest that interventions that improve symptoms in COPD also reduce dynamic hyperinflation [14-16]. Moreover, dynamic hyperinflation is closely linked with limitation of the activities of daily living [17].

The technique for assessing dynamic hyperinflation by inspiratory capacity (IC) measurements during exercise is not entirely straightforward; the individual breathes in to total lung capacity (TLC), which has been shown to remain constant during exercise, at intervals throughout the test, and as the EELV rises, the IC falls. However, it requires the subject to make a maximal IC manoeuvre while they exercise; how satisfactorily patients do this has not been assessed. Conversely, if patients have not achieved a true TLC before exercise, but generate a maximal IC during exercise, then dynamic hyperinflation would be underestimated. Moreover, to accurately measure dynamic hyperinflation with the IC technique, it is important to ensure that the manoeuvre is started from functional residual capacity, and this "static" concept can be hard to evaluate during the tachypnoea that accompanies exercise. These and other technical reservations can be overcome (albeit at a cost) by the use of alternative technologies that make continuous measures of lung volume, such as optoelectronic plethysmography [18]. However, the greater scientific problem is that exercise, through flow limitation, drives both dynamic hyperinflation (i.e. increased EELV) and tidal volume increases, which cause increased EILV. Thus, dissecting the relative contribution of the two as aetiological factors of dyspnoea or exercise limitation through other mechanisms [19] present serious difficulties but could have rewards, since their mechanisms are potentially different.

The assessment of dynamic lung volumes has developed from a research technique employed by investigators focussing on physiological mechanisms to an outcome measure with 
acceptable responsiveness and repeatability, which has been employed in large-scale multicentre trials of newer inhaled bronchodilators. In this issue of the European Respiratory Journal, GUENETTE et al. [20] report how they exploited existing large trial databases to further refine our understanding of the role of lung volume changes during exercise and, in particular, to address the outstanding question of whether exercise limitation in COPD occurs because of true dynamic hyperinflation (i.e. the increase in EELV occurring during exercise) or whether it is in fact changes in end-inspiratory lung volumes, expressed either as EILV or as inspiratory reserve volume (IRV), that are the main contributors to breathlessness. To compare the role of these two parameters, from where the breath starts and where it ends, they examined patients prospectively studied in two multicentre, double-blind clinical studies designed to evaluate the clinical benefit of tiotropium, a long-acting antimuscarinic bronchodilator. As expected, a minority, some $15 \%$, of patients were identified as nonhyperinflators (for this purpose, strictly defined as no rise in EELV, as manifested by no fall in IC). These patients were then matched in a case-control fashion to subjects from the remaining participants. The hyperinflators demonstrated an early fall in IC (achieving $>70 \%$ of their hyperinflation in this time); however, the exercise performance of both groups remained identical until tidal volume plateaued (and, thus, decreased as a function of increasing minute ventilation). Based on these data, the authors concluded that it is EILV, rather than EELV, that represents the constraining factor in COPD. This is plausible, since the pressure-volume characteristics of the respiratory system are most disadvantageous at this point, requiring high levels of neural drive [21], and it is likely that this drive also causes dyspnoea [4].

From a treatment perspective, the present data would suggest significant benefit is achievable either if the system can be allowed to work more comfortably at very high lung volumes or if it can be prevented from reaching them by reducing EELV or tidal volume (thus reducing EILV). Some interventions that reduce both EELV and EILV have already been noted, but beneficial results also occur where metabolic demand is reduced through training and improved muscle metabolism $[22,23]$. Further experimental data supporting the specific relevance of EILV is provided by the observation that augmenting inspiratory muscle action at high lung volumes, for example by the use of noninvasive inspiratory pressure support, can extend exercise duration [24] and increase peak work load [25]. Conceptually, interventions that increase respiratory system compliance at high lung volumes might also be effective; how this can be achieved is more difficult, although we have previously reported an increase in chest wall compliance in COPD patients receiving nocturnal noninvasive inspiratory pressure support directly supervised as an in-patient [26], and this therapy is recently reported to be an effective adjunct to rehabilitation [27].

In conclusion, going forward, it seems that when evaluating lung volumes during exercise, a focus on IRV may be most appropriate. Although further work will be required to address this, this finding is to be welcomed not least because the measurements are easier. Looking back, Christie may well have summed the case neatly by his observation that patients with COPD have an "inability to produce any significant increase in inspiratory depth" and that this limits their capacity [11].

\section{STATEMENT OF INTEREST}

None declared.

\section{REFERENCES}

1 Man WD, Soliman MG, Gearing J, et al. Symptoms and quadriceps fatigability after walking and cycling in chronic obstructive pulmonary disease. Am J Respir Crit Care Med 2003; 168: 562-567.

2 Hogg JC, Chu F, Utokaparch S, et al. The nature of small-airway obstruction in chronic obstructive pulmonary disease. $N$ Engl J Med 2004; 350: 2645-2653.

3 Jackson AS, Hopkinson N. Skeletal muscle in chronic obstructive pulmonary disease. Clin Pulm Med 2009; 16: 61-67.

4 Jolley CJ, Luo YM, Steier J, et al. Neural respiratory drive in healthy subjects and in COPD. Eur Respir J 2009; 33: 289-297.

5 Hopkinson NS, Sharshar T, Ross ET, et al. Corticospinal control of respiratory muscles in chronic obstructive pulmonary disease. Respir Physiol Neurobiol 2004; 141: 1-12.

6 Kelly JL, Crowley O, Smith C, et al. Factors associated with health status assessed using the COPD assessment test score in outpatients with COPD. Respiration 2012; in Press.

7 O'Donnell DE, Forkert L, Webb KA. Evaluation of bronchodilator responses in patients with "irreversible" emphysema. Eur Respir J 2001; 18: 914-920.

8 Man WD, Mustfa N, Nikoletou D, et al. Effect of salmeterol on respiratory muscle activity during exercise in poorly reversible COPD. Thorax 2004; 59: 471-476.

9 Campbell EJM, Green JH. The variations in intraabdominal pressure and the activity of the abdominal muscles during breathing; a study in man. J Physiol (Lond) 1953; 122: 282-290.

10 Polkey MI, Hamnegard CH, Hughes PD, et al. Influence of acute lung volume change on contractile properties of human diaphragm. J Appl Physiol 1998; 85: 1322-1328.

11 Christie RV. The elastic properties of the emphysematous lung and their clinical significance. J Clin Invest 1934; 13: 295-321.

12 Potter WA, Olafsson S, Hyatt RE. Ventilatory mechanics and expiratory flow limitation during exercise in patients with obstructive lung disease. J Clin Invest 1971; 50: 910-919.

13 O'Donnell DE, Bertley JC, Chau LK, et al. Qualitative aspects of exertional breathlessness in chronic airflow limitation: pathophysiologic mechanisms. Am J Respir Crit Care Med 1997; 155: 109-115.

14 Somfay A, Porszasz J, Lee SM, et al. Dose-response effect of oxygen on hyperinflation and exercise endurance in non-hypoxemic COPD patients. Eur Respir J 2001; 18: 77-84.

15 O'Donnell DE, Voduc N, Fitzpatrick M, et al. Effect of salmeterol on the ventilatory response to exercise in chronic obstructive pulmonary disease. Eur Respir J 2004; 24: 86-94.

16 Hopkinson NS, Toma TP, Hansell DM, et al. Effect of bronchoscopic lung volume reduction on dynamic hyperinflation and exercise in emphysema. Am J Respir Crit Care Med 2005; 171: 453-460.

17 Garcia-Rio F, Lores V, Mediano O, et al. Daily physical activity in patients with chronic obstructive pulmonary disease is mainly associated with dynamic hyperinflation. Am J Respir Crit Care Med 2009; 180: 506-512.

18 Georgiadou O, Vogiatzis I, Stratakos G, et al. Effects of rehabilitation on chest wall volume regulation during exercise in COPD patients. Eur Respir J 2007; 29: 284-291.

19 Vassaux C, Torre-Bouscoulet L, Zeineldine S, et al. Effects of hyperinflation on the oxygen pulse as a marker of cardiac performance in COPD. Eur Respir J 2008; 32: 1275-1282.

20 Guenette JA, Webb KA, O'Donnell DE. Does dynamic hyperinflation contribute to dyspnoea during exercise in patients with COPD? Eur Respir J 2012; 40: 322-329.

21 Qin YY, Steier J, Jolley C, et al. Efficiency of neural drive during exercise in patients with COPD and healthy subjects. Chest 2010; 138: 1309-1315. 
22 Puente-Maestu L, Abad YM, Pedraza F, et al. A controlled trial of the effects of leg training on breathing pattern and dynamic hyperinflation in severe COPD. Lung 2006; 184: 159-167.

23 Casaburi R, Porszasz J, Burns MR, et al. Physiologic benefits of exercise training in rehabilitation of patients with severe chronic obstructive pulmonary disease. Am J Respir Crit Care Med 1997; 155: 1541-1551.

24 Polkey MI, Hawkins P, Kyroussis D, et al. Inspiratory pressure support prolongs exercise induced lactataemia in severe COPD. Thorax 2000; 55: 547-549.
25 Hawkins P, Johnson LC, Nikoletou D, et al. Proportional assist ventilation as an aid to exercise training in severe chronic obstructive pulmonary disease. Thorax 2002; 57: 853-859.

26 Nickol AH, Hart N, Hopkinson NS, et al. Mechanisms of improvement of respiratory failure in patients with COPD treated with NIV. Int J Chron Obstruct Pulmon Dis 2008; 3: 453-462.

27 Duiverman ML, Wempe JB, Bladder G, et al. Two-year homebased nocturnal noninvasive ventilation added to rehabilitation in chronic obstructive pulmonary disease patients: a randomized controlled trial. Respir Res 2011; 12: 112. 